Dicle Tıp Dergisi / Dicle Med J (2019) 46 (3) : 397 - 404

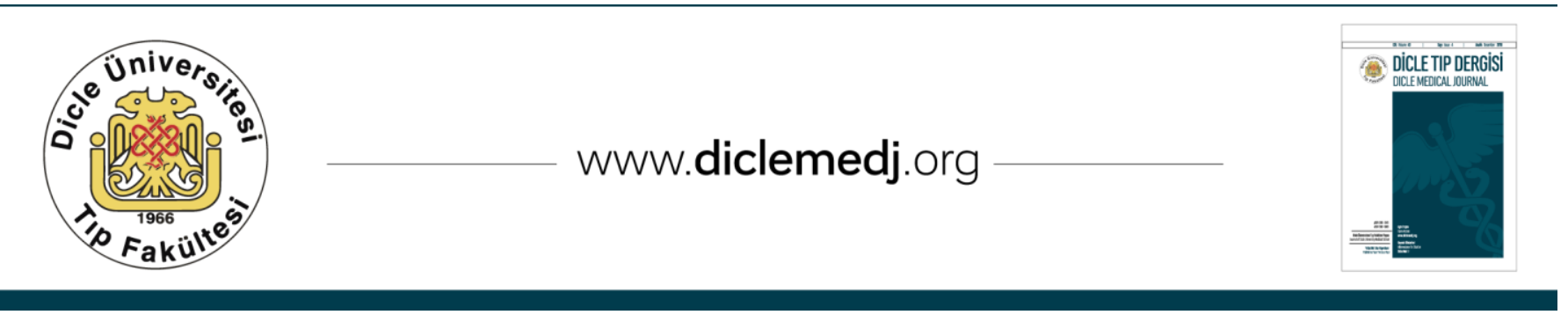

Özgün Araștırma / Original Article

\title{
Alt ekstremite kısalıklarının uzayabilen intramedüller çivi ile tedavisinin klinik ve radyolojik sonuçlarının değerlendirilmesi
}

\author{
Mesut Karıksız $^{1}$, Abdülkadir Sarı², Özgür Karakoyun ${ }^{3}$ \\ 1 Sağlık Bilimleri Üniversitesi Gazi Yaşargil Eğitim ve Araștırma Hastanesi Kayapınar/Diyarbakır, Türkiye ORCID: 0000-0002-9632-7694 \\ 2 Namık Kemal Üniversitesi Eğitim ve Araștırma Hastanesi, Ortopedi ve Travmatoloji Kliniği Tekirdağ, TürkiyeORCID:0000-0003-3416-5666 \\ 3 Namık Kemal Üniversitesi Ĕgitim ve Araştırma Hastanesi, Ortopedi ve Travmatoloji Kliniği Tekirdă̆, TürkiyeORCID:0000-0002-5772-5630
}

Geliş: 22.11.2018, Revizyon: 02.05.2019; Kabul Tarihi: 21.06.2019

Öz

Amaç: Alt ekstremite kısalıklarının tedavisinde yeni bir yöntem olan uzayabilen intramedüller çivi ile ekstremite uzatmaları yapılan hastaların klinik ve radyolojik sonuçlarının değerlendirilmesi amaçlanmıştır.

Yöntemler: Retrospektif olan bu çalışmada, kliniğimize 2013-2016 yılları arasında alt ekstremitede kısalık nedeniyle başvuran hastalardan uzayabilen intramedüller çivi ile ekstremite uzatma operasyonu yapılan 12 hastaya ait 13 ekstremitenin klinik ve radyolojik sonuçları değerlendirilmiştir. Hastaların ortalama yaşı 26,9 (dağılım:13-51), cinsiyet dağılımı 2 erkek, 10 kadındır. Kemik dağılımı 5 tibia, 8 femur olarak tespit edilmiştir. Hastaların karşı ekstremiteye göre kısalığı ortalama olarak 54,6 mm (dağılım: 30-140 mm)ve taraf olarak dağılımı ise 8 sağ, 5 soldur. Hastalardan 3 tanesinde post travmatik kısalık, 6 tanesinde konjenital kısalık ve 3 tanesinde de opere gelişimsel kalça displazisine sekonder kısalık tespit edilmiştir.

Bulgular: Hastaların ortalama takip süresi 35,7 (dağılım: 12-36) aydır. Ortalama distraksiyon indeksleri 1,12 (dağılım:1,05-1,52) gün/mmdir. Ortalama kemik iyileşme indeksi 37,3 (dağılım: 27-70) gün/cm olarak hesaplanmış olup, ortalama uzatma miktarı 5,15 (dağılım: 3-10) cm olarak gözlenmiştir. Paleyinintramedüller çivi üzerinde uzatma hastaları için kullandığı kemik ve fonksiyonel skorlamasına göre hastalar değerlendirildiğinde, hepsinin fonksiyonel skoru çok iyi, 11 hastanın kemik skoru çok iyi ve 1 hastanın kemik skoru iyi olarak değerlendirilmiştir. Tüm hastalarda tam kaynama sağlanmış olup, sadece bir hastada gecikmiş kaynama saptanmıştır. Bu hastada da greft tatbiki ihtiyacı olmadan kontrollerde kaynama gözlenmiştir. Tüm hastaların eklem hareket açıklıkları operasyon öncesi değerlerine ulaşmıştır. Tüm hastalarda post op medial aks sapması (MAD) fonksiyonel sınırlar içerisinde gözlemlenmiştir. Bir hastanın konsolidasyon safhasında intramedüller çivisinde kırık saptanmış ve plak vida ile desteklenmiştir. Hiç bir hastada derin enfeksiyon tespit edilmemiştir.

Sonuç: Alt ekstremite kısalığı olan hastaların tedavisinde uzayabilen intramedüller çivi ile uzatma operasyonlarının klinik ve radyolojik sonuçlarının tatmin edici olduğu söylenebilir.

Anahtar kelimeler: Alt Ekstremite, Kısalık, Uzayabilen İntramedüller Çivi.

DOI: 10.5798/dicletip.620319

Yazışma Adresi / Correspondence: Mesut Karıksız, Sağlık Bilimleri Üniversitesi Gazi Yaşargil Eğitim ve Araştırma Hastanesi Elazığ Yolu 10. Km Üçkuyular Mevkii 21070 Kayapınar/Diyarbakır,Türkiye e-mail: mesutkariksiz@gmail.com 


\title{
Evaluation of the clinical and radiological outcomes of lengthening intramedullary nail treatment in the lower limb length discrepancies
}

\begin{abstract}
Objective: The aim of this study was to evaluate the clinical and radiological outcomes of patients in lengthening intramedullary nails as a new method to treat lower limb discrepancies.

Method: In our retrospective study, we evaluated the clinical and radiological results of 13 extremities of 12 patients who applied to our clinic due to a discrepancy of the lower extremity between 2013-2016 and underwent extremity lengthening with lengthening nail. Mean age of patient the patients was 26, 9 (range: 13-51). Gender distribution was as 2 males and 10 females. Bone distribution was determined as 5 tibias and 8 femurs. The mean discrepancy of the patients was $54.61 \mathrm{~mm}$ (range: $30-140 \mathrm{~mm}$ ). The side distribution of the patients was as 8 right and 5 left. Three of our patients had post-traumatic shortness, 6 had congenital discrepancies and left 3 cases had discrepancies secondary to developmental hip dysplasia.

Findings: The mean follow-up period of our patients was 35.7 (range: 12-36) months. The mean distraction index of our patients was 1.12 (range: 1.05-1.52) days $/ \mathrm{mm}$. Mean bone healing index was 37.3 (range: $27-70$ ) days $/ \mathrm{cm}$. The mean length of extension was 5.15 (range: $3-10$ ) $\mathrm{cm}$. When the patients were evaluated according to the bone and functional scoring used by Paley for intramedullary lengthening nails, all our patients were found to have very good functional scores, where 11 patients had very good bone scores and 1 patient had a good bone score. Complete union was achieved in all patients. In one of our patients, delayed union was detected. The range of motion of all patients reached preoperative values. Post-op medial axis deviation (MAD) was determined to be within the functional limits in all our patients. In the consolidation phase, a fracture was detected on the intramedullary nail in one of our patients, and osteosynthesis was supported with plate screw. None of our patients had deep infection.

Conclusion: The clinical and radiological outcomes of intramedullary lengthening nails and lengthening surgery can be considered as satisfactory in the treatment of patients with lower extremity discrepancy.
\end{abstract}

Keywords: Lower extremity, discrepancy, intramedullary lengthening nail.

\section{GíRiş}

Ekstremite uzatılması distraksiyono steogenezisi tekniği ile güvenilir bir şekilde yapılmaktadır. Distraksiyono steogenezisi distraksiyon safhası ve konsolidasyon safhası olmak üzeri iki safhadan oluşmaktadır. Bu teknik birçok klinikte halen en sık eksternal fiksatörler ile yapılmaktadır. Eksternal fiksatör uygulamalarının pin dibi enfeksiyonu, eklem sertliği, kontraktürler, kozmetik problemler, fiksatör çıkartılması sonucu kırıkların oluşması gibi bir takım dezavantajları görülmektedir ${ }^{1}$. Bu komplikasyonların en önemli nedeni, eksternal fiksatörün hasta üzerinde kalış süresinin uzamasından kaynaklanmaktadır.

$\mathrm{Bu}$ komplikasyonları azaltmak için distraksiyon safhasını eksternal fiksatör ile sağladıktan sonra, konsolidasyon safhasını intramedüller çivi veya plak ile tamamlayan yöntemler geliştirilmiştir. Bunlara örnek olarak; İntramedüler çivi üzerinde uzatma, uzatma sonrasında intramedüller çivi veya plak vida tatbiki ile konsolidasyon safhasının tamamlanmasını içermektedir.

İlerleyen teknolojiler ile intramedüller uzayabilen çiviler üretilmeye başlanmıştır. Günümüzde tamamıla intramedüller distraksiyono steogenezi için kullanılan çiviler Albizzia (Depuy, Villeurbanne, Fransa), ISKD (Orthofixinc.), Fitbone (Betz ve Baumgart) ve Precise (Ellipsetechnology USA) çivileridir. Bu çivilerden Albizzia ve ISKD mekanik olarak uzama sağlamaktadır ${ }^{2,3,4}$. Fitbone çivisi motorlu bir mekanizma ile uzatma sağlarken, Precise çivisi manyetik uzatma sağlar. Motorize ve mekanik uzayabilen çiviler ile sadece uzatma yapılırken manyetik uzatma çivisi ile hem uzatma hem de kısaltma yapılabilmektedir.

İntramedüller uzayabilen çivilerin, uzatılması planlanan kemikte intramedüller kanalı dar 
olan, kemikte akut düzelmeye izin vermeyecek derecede deformitesi olan, derin yumuşak doku enfeksiyonu veya kemik enfeksiyonu olan hastalarda kullanılması uygun değildir. $\mathrm{Bu}$ çalışmada Namık Kemal Üniversitesi Tıp Fakültesi Ortopedi ve Travmatoloji kliniğinde uzayabilen çivi kullanılmasında kontrendike olmayan hastaların ekstremite kısalığının tedavisinde bu yöntem kullanılmış olup uzayabilen çivi ile uzatma yapılan hastaların klinik ve radyolojik sonuçları incelenmiştir.

\section{YÖNTEMLER}

Kliniğimize 2013-2016 yılları arasında alt ekstremite kısalığ hastaların ortopedik muayenesi ve radyolojik incelemeleri sonucunda uygun bulunan 12 (2 erkek, 10 kadın) hastanın 13 (8 Femur, 5 Tibia) alt ekstremitesi uzayabilen intramedüller çivi ile uzatma yapıldı (Tablo 1). Hastaların ortalama yaşı 26,9 (dağılım:13-51). Hastaların karşı ekstremiteye göre kısalığı çekilen ortoröntgenografi ile ortalama olarak $54,6 \mathrm{~mm}$ (dağılım:30-140 $\mathrm{mm}$ ) olarak ölçüldü. Hastaların taraf olarak dağılımı 8 sağ, 5 soldur. Hastalardan 3'ünde post travmatik kısalık, 6'sında konjenital kısalık ve 3'ünde de opere gelişimsel kalça displazisine sekonder kısalık saptandl.

Hasta seçimi ölçütleri aşağıdaki kriterler baz alınarak yapılmıştır.

-Kısalık farkının en az $3 \mathrm{~cm}$ olması,

-Son beş yılda derin yumuşak doku veya osteomyelit geçirmemiş olması,

-Uzatılacak segmentin bir alt ve bir üst ekleminde instabilite olmaması,

- Uzatılacak ekstremitenin kas gücünün en az 4/5 olması,

- Diz ekstansiyon defisiti bulunmaması.

Çalışma Namık Kemal Üniversitesi Tıp Fakültesi Girişimsel Olmayan Klinik Araştırmalar Etik Kurul Komitesi'nin onayı alınarak gerçekleştirilmiştir. 17.03.2016 tarihinde toplanan etik kurulda 20164603/10 protokol numarasını almıștır.

\section{CERRAHI TEKNÍK}

Alt ekstremite kısalıklarında uzatma işlemi femur veya tibiadan yapılabilmektedir. Femur proksimalinden antegrad trochanteric veya priformik giriș, distalinden retrograd giriş tanımlanmıştır. Tibia için ise proksimal tibiada nantegrad giriș tanımlanmıștır.

\section{Femurantegrad giriș}

$\mathrm{Bu}$ yaklaşımı genellikle deformiteapeksi proksimalde olan uzatma işlemlerinde veya rotasyonel problemli hastalarda akut düzeltme yapılması halinde tercih ettik.

Antegrad teknik için hasta radyolusent masa üstünde supin pozisyonda yatırıldı. Kılavuz teli yerleştirildi ve çivi kalınlığının $1 \mathrm{~mm}$ üstü olacak şekilde esnek oyucularla oyuldu. Osteotomi hattı çivi giriş yerinin $8 \mathrm{~cm}$ distalinde olacak şekilde çoklu delme yöntemiyle tamamland. Çivi tatbik edildi ve işlem bittikten sonra kontrol amaciyla $1 \mathrm{~mm}$ uzatma yapildı.

\section{Femur Retrograd giriş}

Retrograd girişi femur proksimalinde girișe izin vermeyecek deformite varlığında, kalça artrodezi varlığında veya distal femoralde formitelerin düzeltilmesi istenen durumlarda tercih ettik.

Retrogradfemoral teknik için hasta radyolusent masa üstünde supin pozisyonda yatırıldı. Osteotomi sonrası rotasyon kontrolü için femur proksimaline 1 schanz ve distaline 1 schanz birbirine paralel olacak şekilde tatbik edildi. Diz 30' fleksiyona getirildi, kılavuz teli infrapatellar retrograd femoral çivi için standart giriş yerinden gönderildi ve distal oymaya başlandı. Femur posterior korteksi sert oyucular ile oyularak şekillendirildi. Osteotomi çoklu delme yöntemiyle tamamlandı. Çivi tatbik edildi ve schanz vidalarıyla rotasyon ayarlandı. 
Distalkilitme kılavuz yardımıyla, proksimal kilitleme serbest kilitlendi (şekil 1).

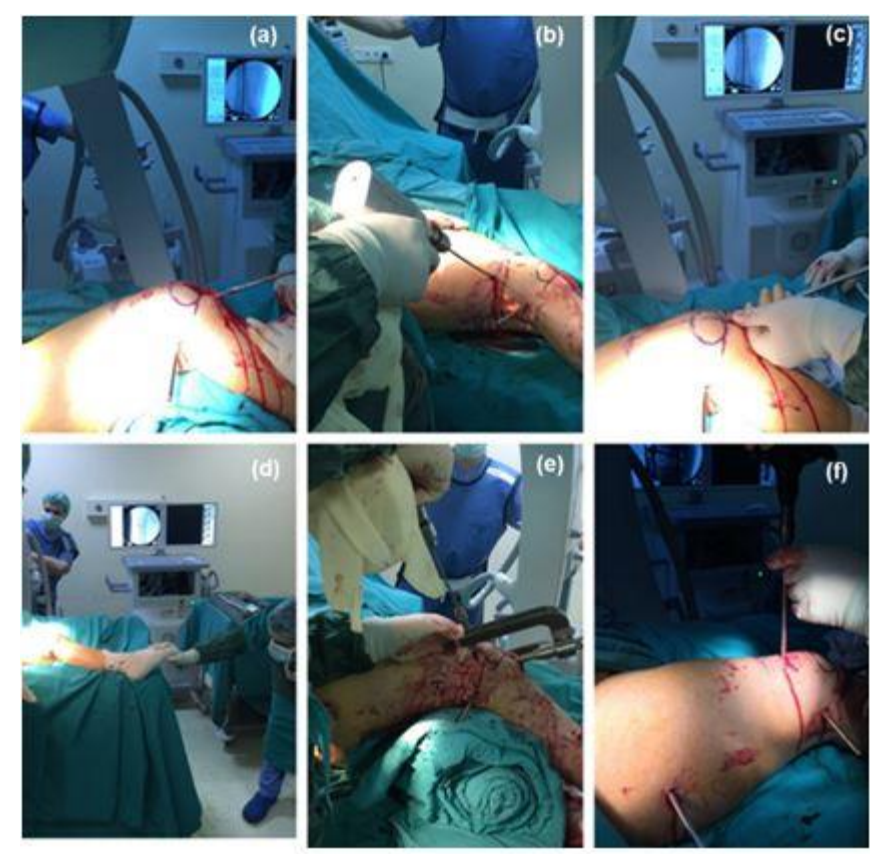

Şekil 1.a) femur distaline schanz yerleştirilmesi,

1.b) multipl drill ile osteotomi

1.c) retrograd çivi tatbiki

1.d) rotasyon kontrolü

1.e) distal vida deliklerinin drillenmesi

1.f) distal vida deliklerinin kilitlenmesi

\section{Tibia}

Tibiadan uzatma yapılırken 10 dereceye kadar olan deformitelerde akut olarak düzeltilebilmektedir. Deformite düzeltilirken block vidası kullanılır, ayrıca fiksatör yardımıyla veya plak yardımı ile de deformite düzeltilip çivi tatbik edilebilir.

Supin pozisyonunda radyografik grip üstünde skopi kontrolünde, Fibula $1 / 3$ orta seviye lateralden $1 \mathrm{~cm}$ insizyonla girilip oyucu ve osteotom yardımıyla fibula osteotomize edildi ve yaklaşık $1 \mathrm{~cm}$ 'lik fibula kısmı rezeke edildi. Distaltibia ve fibula arasina 4,5 mm syndesmos vidası gönderildi. Ardından diz hyperfleksiyona getirildi ve parapatellar $3 \mathrm{~cm}$ insizyonla girilip kllavuz teli gönderildi. Önceden belirlenen osteotomi hattı $1 \mathrm{~cm}$ insizyonla girilip periost sıyrılıp çoklu delme yapıldı. Kılavuz teli üzerinden esnek oyucu gönderilip oyma işlemine başlandı ve sert oyucularla tamamlandı. Oyma işlemi çivi boyutunun $1 \mathrm{~mm}$ üstü olacak şekilde tamamlandı. Eğer deformite düzeltilecekse block vidası skopi kontrolünde önceden belirlenen yere kondu. İntramedüller çivi osteotomi hattının proksimaline yerleştirildi ve osteotomi hattına ostetom yardımıyla girilerek osteotomi tamamlandı ve çivi distale ilerletildi(Şekil 2).
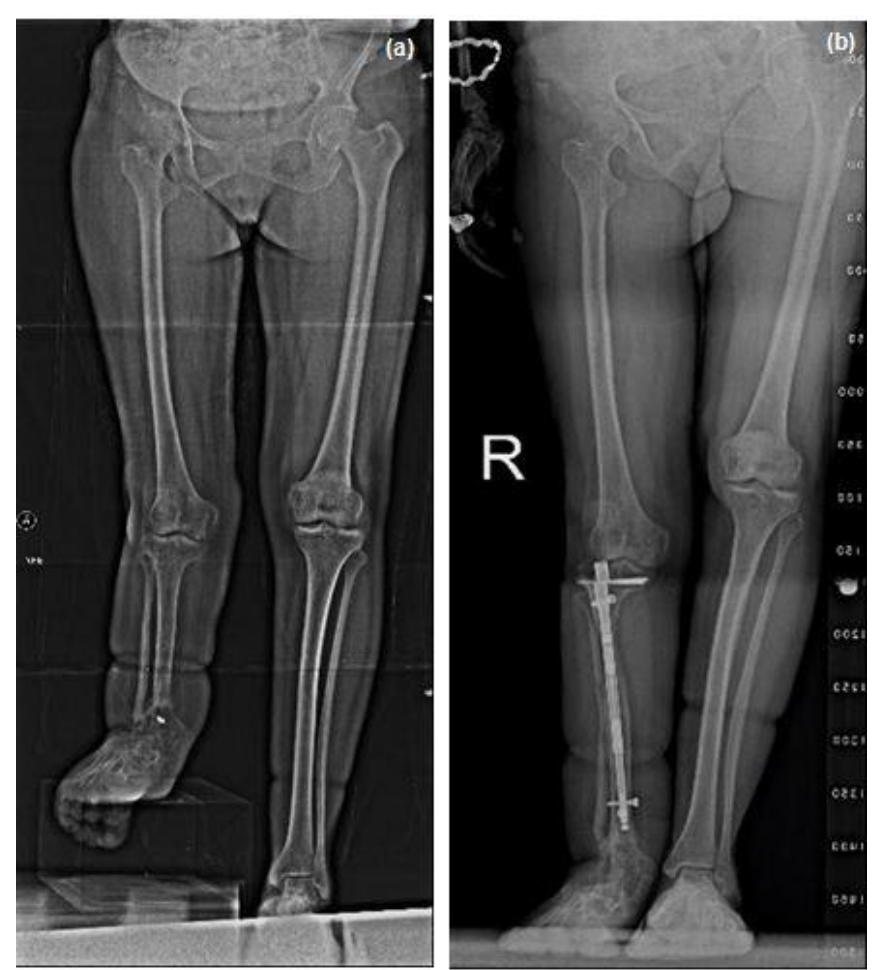

Şekil 2.a) Konjenital tibia psödoartrozu ameliyat öncesi

2.b) Ameliyat sonrası tibiada sağlanan $10 \mathrm{~cm}$ 'lik uzama

\section{Ameliyat sonrası bakım}

Tüm hastalar ameliyat sonrası 1. gün kısmi yük verilerek destek yardımıyla yürütüldü. Ameliyat sonrası 7. günde uzatma işlemine başlandı. Uzatma işlemi 6 saatte bir 0,25 mm olacak şekilde günde $1 \mathrm{~mm}$ yapıldı. Erken dönem radyografik takiplerde bazı hastalarda kemik kallus oluşumunun hızlı olduğu görüldü ve osteotomi hattında erken kaynama olmaması açısından uzatma günde 1,5 mm'ye çıkartıldı. Takiplerde kemik kallusunun uygun 
olduğu görüldü, uzatma miktarı 1 mm'ye düşürüldü ve günde $1 \mathrm{~mm}$ olacak şekilde devam edildi. Distraksiyon safhasında hastalar haftalık kontrollere çağırıldı. Konsolidasyon safhasinda ise aylı kontroller yapıldı. Takiplerde Ap ve lateral grafilerde 3 korteks te kortikalizasyon görünce tam yük verildi.

Tablo 1. Çalıșmaya Örneklem Oluşturan Hastalara Ait Özellikler

\begin{tabular}{|c|c|c|c|c|c|c|c|c|c|c|c|c|}
\hline No & Yaş & Cinsiyet & $\begin{array}{l}\text { Taraf/ } \\
\text { Kemik }\end{array}$ & $\begin{array}{l}\text { Antegrad/ } \\
\text { Retrograd }\end{array}$ & Etiyoloji & $\begin{array}{c}\text { Kisalık } \\
(\mathrm{mm})\end{array}$ & $\begin{array}{c}\text { Uzatma } \\
\text { miktarı } \\
(\mathrm{mm})\end{array}$ & $\begin{array}{c}\text { Fonksiyonel } \\
\text { skor }\end{array}$ & $\begin{array}{c}\text { Kemik } \\
\text { skoru }\end{array}$ & $\begin{array}{c}\text { Distraksiyon } \\
\text { indeksi } \\
\text { (gün/mm) }\end{array}$ & $\begin{array}{c}\text { Konsolidasyon } \\
\text { indeksi (gün/cm) }\end{array}$ & Komplikasyon \\
\hline 1 & 35 & kadın & $\mathrm{R} / \mathrm{T}$ & antegrad & konjenital & 140 & 100 & çok iyi & çok iyi & 1,07 & 27 & \\
\hline 2 & 44 & kadın & $\mathrm{R} / \mathrm{F}$ & retrograd & operegkd(tkp) & 40 & 40 & çok iyi & çok iyi & 1,05 & 33 & \\
\hline 3 & 40 & erkek & $\mathrm{L} / \mathrm{T}$ & antegrad & posttravmatik & 30 & 30 & çok iyi & İyi & 1,06 & 70 & $\begin{array}{l}\text { Gecikmiş } \\
\text { kaynama }\end{array}$ \\
\hline 4 & 51 & kadın & $\mathrm{L} / \mathrm{F}$ & retrograd & operegkd(tkp) & 40 & 40 & çok iyi & çok iyi & 1,08 & 43 & \\
\hline 5 & 24 & kadın & $\mathrm{L} / \mathrm{T}$ & antegrad & posttravmatik & 50 & 50 & çok iyi & çok iyi & 1,52 & 34 & \\
\hline 6 & 19 & erkek & $\mathrm{R} / \mathrm{T}$ & antegrad & konjenital & 50 & 50 & çok iyi & çok iyi & 1,2 & 36 & $\begin{array}{l}\text { İmplant } \\
\text { yetmezliği }\end{array}$ \\
\hline 7 & 19 & kadın & $\mathrm{R} / \mathrm{F}$ & retrograd & posttravmatik & 60 & 60 & çok iyi & çok iyi & 1,06 & 32 & \\
\hline 8 & 30 & kadın & $\mathrm{R} / \mathrm{F}$ & retrograd & operegkd(tkp) & 50 & 50 & çok iyi & çok iyi & 1,1 & 36 & \\
\hline 9 & 13 & kadın & $\mathrm{L} / \mathrm{F}$ & antegrad & konjenital & 30 & 30 & çok iyi & çok iyi & 1,16 & 32 & \\
\hline 10 & 17 & kadın & $\mathrm{R} / \mathrm{F}$ & antegrad & Konj & 30 & 30 & çok iyi & çok iyi & 1,1 & 30 & \\
\hline 11 & 21 & kadın & BİL/F & antegrad & akondroplazi & 80 & 80 & çok iyi & çok iyi & 1,08 & 40,40 & \\
\hline 12 & 20 & kadın & $\mathrm{R} / \mathrm{T}$ & antegrad & konjenital & 30 & 30 & çok iyi & çok iyi & 1.07 & 32 & \\
\hline
\end{tabular}

\section{SONUÇLAR}

Hastaların ortalama takip süresi 35,7 (dağılım: 12-54) ay olarak tespit edildi. Hastaların ortalama distraksiyon indeksleri (distraksiyon yapılan hedef sahanın milimetre bașına düșen gün sayısı) 1,1 (dağılım: 1.05-1.52) gün $/ \mathrm{mm}$, ortalama kemik iyileșme indeksi (distraksiyon yapılan hedef bölge için konsolide olan cm başına düşen gün sayısı) 37,3 (dağılım: 27-70) gün/cm olarak hesaplandı. Ortalama uzatma miktarı 5,15 (dağılım: 3-10) cm olarak tespit edildi. Paleyin intramedüller çivi üzerinden uzatma hastaları için kullandığı kemik ve fonksiyonel skorlamasına göre, bu skorlamada hastaların eklem hareket açıklıkları, medial aks sapması, mekanik akslar, ağrı, yürüyüş, günlük yaşama ve işe dönüş değerlendirildi, tümünün fonksiyonel skoru çok iyi, 11 hastanın kemik skoru çok iyi ve 1 hastanın kemik skoru iyi olarak saptandi ${ }^{5}$. Tüm hastalarda tam kaynama sağlandı sadece bir hastada gecikmiş kaynama tespit edildi. Bu hastada da greft tatbiki ihtiyacı olmadan kontrollerde kaynama izlendi. Tüm hastaların eklem hareket açıklıkları operasyon öncesi değerlerine ulaştı. Bütün hastalarda post op medial aks sapması (MAD) fonksiyonel sınırlar içerisinde tespit edildi. Bir hastanın konsolidasyon safhasında intramedüller çivisinde kırık tespit edildi ve plak vida ile desteklendi. Kalça endo protezi bulunan 3 hastada uzatma esnasında kalça endoprotezinde çlkık, enfeksiyon veya ağrı gibi komplikasyonlar ile karşılaşılmadı. Hiç bir hastada derin enfeksiyon tespit edilmedi. 


\section{TARTIŞMA}

Distraksiyon osteogenezi yöntemi kullanılarak alt ekstremite kısalık farkının giderilmesini sağlayan sirküler veya monolateral eksternal fiksatörler uzatma cerrahisinde en çok kullanılan ortopedik enstrümanlardır. Bununla beraber eksternal fiksatör ile yapılan uzatma operasyonlarına birçok farklı komplikasyon eşlik etmektedir ve literatürde hasta başına 1.0-2.8 oranında komplikasyon bildirilmiștir ${ }^{6,7}$. Pin dibi enfeksiyonları, derin yumuşak doku enfeksiyonları, schanz çivileri ve kischner tellerinden kaynaklanan ağrı, pratikte en sık karşılaşılan ve operasyon sonrası hasta memnuniyetini azaltan problemlerin başında gelmektedir. Uzayabilen intramedüller çivilerin kullanılmasıyla bu tür komplikasyonların önüne geçilmiștir. Bu çalışmada hiçbir hastada enfeksiyon gelişmemiştir.

Eklem kontraktürleri yine eksternal fiksatör ile ekstremite uzatmada sıkça karşılaşılan sorunlardandır. Uzayabilen intramedüller çiviler postop 1. günde eklem hareket açılklğ egzersizleri başlanmaya imkan sağlamaktadır. Bu sebeple bu çalışmada hiçbir hastada eklem konraktürü gelişmedi. Eksternal fiksatörler ile yapılan uzatma işlemleri sonrasında sekonder aksiyel deformiteler oluşabilmekte ve fiksatör çıkarma işlemi sonrasında yeni oluşan kemik dokusunda deformite ve kırıklar oluşabilmektedir ${ }^{6,7}$. Uzayabilen intramedüller çiviler ekstremite uzatması bittikten sonra çıkarılmadığı için distraksiyon bölgesinde deformite ve kırık gelişmemektedir.

Eksternal fiksatörlerin hasta üzerinde kalış süresini kısaltmak için son yıllarda yeni teknikler geliştirilmiştir. Bost ve Larsen (1956), eksternal fiksatör uygulamaları sonrası, dizilim problemlerini önlemek için intramedüller çivi ile geçici olarak uyguladığı eksternal fiksatörü kombine etmişlerdir8. Paley ve ark. (1997), tarif ettikleri intramedüller çivi üzerinde femur uzatma tekniği ile yapılan distraksiyon osteogenezi sonuçlarında, eksternal fiksatör süresinde kısalma ve düşük enfeksiyon oranları bildirmişlerdir9. Küçükkaya ve ark. (2013), Retrograde femur çivisi üzerinden 3 schanz kullanarak uzatma tekniğini tanımlamış ve schanz sayısının azalmasıyla enfeksiyon oranlarında azalma olduğunu belirlemişlerdir. Kombine teknik olarak anılan bu yeni yöntemler ile sadece uzatma amacıyla değil, aynı zamanda kaynamama veya enfekte kaynamama, defektli kaynamama, farklı endikasyonlarda da eksternal fiksatör sürelerini kısaltmak ve çivi dibi enfeksiyonlarını azaltmak amacı ile de kullanılmaktadır ${ }^{10}$. Kombine yöntemlerde, eksternal fiksatör süresi ve enfeksiyon miktarı azalmasına rağmen halen yüksek oranda komplikasyondan bahsedilmektedir ${ }^{11}$. Pediatrik hasta grubunda ise kombine teknik uygulamalarında komplikasyon riskinin erişkinlere göre daha düşük olduğu görülmüştür ${ }^{12}$.

Günümüzde tamamıla intramedüller distraksiyon osteogenezi için kullanılan çiviler Albizzia (Depuy, Villeurbanne, Fransa), ISKD (Orthofixinc.), Fitbone (Betz ve Baumgart) ve Precise (Ellipse technology USA) çivileridir.

Albizzia ve ISKD çivileri uzatma sırasında \%2239 oranında distraksiyonun değişik aşamalarında genel veya epidural anestezi altında mobilizasyon ve çivi rotasyonu tekrar ayarlanması gibi ikinci bir operasyona ihtiyaç duyulabilir. Manipülasyon esnasında sıkça ağrı görülebilmektedir. Çivinin takılarak uzamaması, anestezi altında manipulasyonu gerekebilir. Distraksiyon miktarının ve süresinin kontrolü zordur. Distraksiyonun yavaş olması erken konsolidasyona, hızlı olması ise zayıf rejenerat oluşumuna neden olabilir ${ }^{2,3}$. Oniki (12) vakalık ISKD çivisi ile yapılan çalışmada 4 hastada runaway fenomeni tanımlanmıştır ${ }^{3}$. Bu durum hasta konforunu azaltmakta ve komplikasyon oranını arttırabilmektedir. Literatürde ISKD için bildirilen komplikasyon oranı \%11-47 ve Albizzia çivisi için bildirilen komplikasyon 
oranı \%20 oranındadır ${ }^{13,14}$. Fitbone için en geniş hasta sayılı $(\mathrm{n}=150)$ çalışmada komplikasyon oranı \%13 oranında bildirilmiştir. Motor çalışmaması, kablo sorunları, proksimal kilitleme vidası etrafındaki subtrokanterik kırıklar en sık karşılaşılan komplikasyonlardır ${ }^{15}$. Precise çivisiyle yapılan bazı çalışmalarda çivide arrest ve mekanik problemler bildirilmiştirit6. $\mathrm{Bu}$ çalışmada herhangi bir mekanik problem ve çivi arresti olmamıștır.

Uzatma çivilerinin hepsi uzatma mekanizmalarından dolayı düz bir şekildedir, bu da femoralboving sonucu anterior kortekste sıkışmaya neden olmakta ve proksimal kilit vidasının etrafındaki subtrokanterik kırıklara neden olabilmektedir. Küçükkaya ve ark (2016) bu sorunu posterior kortekste aşırı oyma ile aşmıştır ${ }^{17}$. $\mathrm{Bu}$ çalışmada femurposterior korteksinin sert oyucular ile oyularak şekillendirdiğimizden subtrokanterik kırık saptamadik.

Tibial uzatma hastalarında fibular erken kaynama sonucu fibulada tekrar osteotomi yapılan olgular tanımlanmıştır ${ }^{18}$. Bu çalışmada fibulaosteotomi sonrası $1 \mathrm{~cm}$ 'lik rezeksiyon yapıldığından dolayı erken kaynama ile karşılaşılmamıştır.

İntramedüller çivi ile yapılan uzatmalarda, intramedüller oyma, distraksiyon bölgesinde yeni kemik oluşumunu bozmamaktadır. Rozbruch ve ark. (2008) uzatma sonrasi intramedüller çivi uygulanması tekniği ile klasik ilizarov yöntemi ile uzatma tekniğini karşılaştırdıkları çalışmada klasik ilizarov tekniği ile uzatmada kemik iyileşme indeksini 57 gün/cm, uzatma sonrası çivi uygulaması yönteminde ise $24 \mathrm{gün} / \mathrm{cm}$ olarak bildirmişlerdir ${ }^{19}$. Sadece intramedüller çivi kullanılarak yapılan uzatma çalışmalarında Albizzia çivisi ile 35.2 gün/cm, ISKD çivisi ile 29 gün/cm, Precise çivisi ile 28 gün/cm ve Fitbone çivisi ile 26-42 gün/cm arasında bildirilmiş konsolidasyon indeksleri mevcuttur ${ }^{13-15}$. Bu çalışmada ise literatürle uyumlu olarak 37.3 gün/cm olarak tespit edilmiştir.

Yapılan çalışmalardaki distraksiyon indekslerine bakıldığı zaman, Albizzia çivisi ile 1,3 gün/mm, ISKD çivisi ile 1,2 gün $/ \mathrm{mm}$, Precise çivisi ile 0,9 gün $/ \mathrm{mm}$ ve Fitbone çivisi ile 1,1 gün $/ \mathrm{mm}$ arasında bildirilmiş distraksiyon indeksleri mevcuttur ${ }^{13-15}$. Bu çalışmada ise distraksiyon indeksi literatürlerle uyumlu olarak 1,12 gün/mm olarak tespit edilmiştir.

Alt ekstremite kısalığ tedavisinde uzayabilen intramedüller çivi ile uzatma operasyonlarının klinik ve radyolojik sonuçlarının tatmin edici olduğu ve hasta memnuniyetinin iyi olduğu görülmekle beraber, daha fazla hasta sayısı içeren kapsamlı çalışmalara ihtiyaç olduğu söylenebilir.

$\mathrm{Bu}$ çalışma 28. Ulusal Türk Ortopedi ve Travmatoloji Kongresinde sözlü olarak sunulmuştur (Antalya, 30 Ekim - 4 Kasım 2018)

Çıkar Çatışması Beyanı: Yazarlar çıkar çatışması olmadığını bildirmişlerdir.

Finansal Destek: Bu çalışma her hangi bir fon tarafından desteklenmemiştir.

Declaration of Conflicting Interests:Theau thorsdeclare that theyhavenoconflict of interest.

Financial Disclosure: No financial support was received.

\section{KAYNAKLAR}

1. Paley D. Problems, obstacles, and complications of limbleng then ingby Ilizarov technique. Clin Orthop RelatRes 1990; (250): 81-104.

2. Guichet JM, Deromedis B, Donnan LT. Gradual femoralleng thening with the albizziai in tramedullery nail. JBJS 2003; 85: 838-48.

3. Hankemeier S. LimbLengthening with the Intramedullary Skeletal Kinetic Distractor (ISKD) Oper Orthop Travm 2005; 17: 79-101. 
4. Kucukkaya M, Karakoyun Ö, Sökücü S, Soydan R. Femoral lengthening and deformity correction using the fitbone motorized lengthening nail J Orthop Sci 2015; 20 : 149-54.

5. Paley D, Herzenberg JE, Paremain G, Bhave A. Femoral lengthening over an intramedullary nail. A matchedcase comparison with Ilizarov femoral lengthening. J Bone Joint Surg Am 1997; 79: 1464-80.

6. Simpson AH. Fracture after distraction osteogenesis JBJS 2000; 82: 659-65.

7. Tjernstöm B, O Lerud S, Rehnberg L. Limb lengthening by callus distraction. Complications in 53 cases operated 1980-1991 Acta Orthop Scand 1994; 65: 447-55.

8. Bost FC, Larsen LJ. Experiences with lengthening of the femur over an intramedullery rod JBJS 1956; 38: 56784.

9. Paley D, Herzenberg JE. Femoral lengthening over an intramedullary nail JBJS 1997; 79: 1464-80.

10. Kucukkaya M, Karakoyun O, Kuzgun U. Lengthening over a retrograde nail using 3 Schanzpins. J Orthop Trauma. 2013 Jan; 27(1):e13-7. doi: 10.1097/BOT.0b013e31824a3e66.

11. Tsuchiya H, Tomita K. Limbsalvage using distraction osteogenesis, A classification of the technique JBJS 1997; 79: 403-11.
12. Saraph V, Roposch A. Tbials lengthening over nails in children using modified Ender nails J pediathric Orthop 2004; 13: 383-8.

13. Leidingier B. Limb lengthening with a fully implantable mechanical distraction intramedullary nail ZOIG 2006; 144: 419-26.

14. Hankemeier S. Improved comfort in lower limb lengthening with the intramedullary skeletal distractor AOTS 2004;124: 129-33.

15. Krieg AH. Leg lengthening with a motorized nail in adolescents: an alternative to external fixators Clin Orthop Relat Res 2008; 466189-97.

16. Morrison TA, Sontich JK. Premature consolidation with result antimplant failure using precice femoral nail lengthening: case report 2016 Jan-Mar; 6(1):e2. doi: 10.2106/JBJS.CC.0.00059.

17. Kucukkaya M, Karakoyun Ö, Erol MF. The importance of reaming the posterior femoral cortex before inserting lengthening nails and calculation of the amount of reaming. Journal of Orthopaedic Surgery and Research (2016) 11: 11 DOI 10.1186/s13018016-0345-6.

18. Mohedano A, Castillo A. Relevant advances in bone lengthening research: a bibliometric analysis of the 100 most-cited articles published from 2001 to 2017. 2018 Oct 11. doi: 10.1097/BPB.0000000000000557.

19. Rozbruch SR, Kleinman D, Fragomen AT, İlizarov S. Limb lengthening and then in sertion of an intramedullary nail: a case matched comparison. Clin Orthop Relat Res 2008; 466: 2923-32. 